\title{
PLASTICITY AND WORKABILITY OF ALUMINIUM ALLOY AT WARM TEMPERATURES
}

\author{
KAPUSTOVA, M[aria] \& MARTINKOVIC, M[aros]
}

\begin{abstract}
Warm forming of metal materials represents a lucrative method of precise forming pieces production due to energy and time savings, obtaining of higher surface quality and dimension precision of forming pieces in comparison with hot forming. This contribution provides information about mechanical properties, plasticity and workability of aluminium alloy at warm forming temperatures. Selected temperatures were verified by numeric simulation of upsetting forming process using finite element method.
\end{abstract}

Key words: plasticity, workability, warm forming, numeric simulation, aluminium alloy

\section{INTRODUCTION}

The warm forming process passes at temperatures which are over recovery temperatures but below down hot forging temperatures. This forming process can obtain higher degree deformation in comparison with cold forming. Warm forming passes with partial strain hardening of metal above recovery temperature and below temperature of recrystallization (Forejt \& Piska, 2006). Energy and time savings at warming up (Forcellese \& Gabrielli, 2000) and higher surface quality and dimension precision of forming pieces after forming in comparison with hot forming are important arguments for investigation of properties of aluminium alloy at warm forming temperatures (Novotny, 2000). This information is necessary for further development of warm forming (Pernis, 2007).

\section{EXPERIMENT}

The subject of plasticity and workability research at warm forming temperatures is aluminium alloy $\mathrm{AlSiMg}$ type, its chemical composition is included in Table 1. This alloy, which belongs to the group " 6000 " of aluminium alloys, is determined primarily for hot forming. The alloy was in natural state, without any heat treatment (for instant solution treatment).

Suitability of examined Al alloy for warm bulk forming was verified by tensile test at higher temperatures (according to standard STN EN 10002-5). Cylindrical bar specimens were used for tensile test. The bar length was $80 \mathrm{~mm}$, diameter 8 $\mathrm{mm}$. The specimens were tested at temperatures 20, 150, 200 and $250^{\circ} \mathrm{C}$. At each temperature three specimens were tested.

\begin{tabular}{|c|c|c|c|c|c|c|c|}
\hline Elemets & $\mathrm{Si}$ & $\mathrm{Mg}$ & $\mathrm{Fe}$ & $\mathrm{Cu}$ & $\mathrm{Mn}$ & $\mathrm{Cr}$ & $\mathrm{Al}$ \\
\cline { 2 - 8 } & \multicolumn{7}{|c|}{ wt.\% } \\
\hline $\min$ & 0,45 & 0,4 & & & & & \\
$\max$ & 0,8 & 0,8 & 0,3 & 0,1 & 0,1 & 0,1 & bal \\
\hline
\end{tabular}

Tab. 1. Chemical composition aluminium alloy

\section{EXPERIMENTAL RESULTS}

Strength limit $R_{m}$, characteristics of plasticity for workability at higher temperature (reduction of area Z, index of plasticity to rupture according to Kolmogorov $\lambda_{R}$, ductility A, Paur`s index of plasticity $\mathrm{D}_{\mathrm{sm}}$ ) and exponent of strain hardness $\mathrm{n}$ were calculated from measured results on three tested specimens at each tested temperatures.

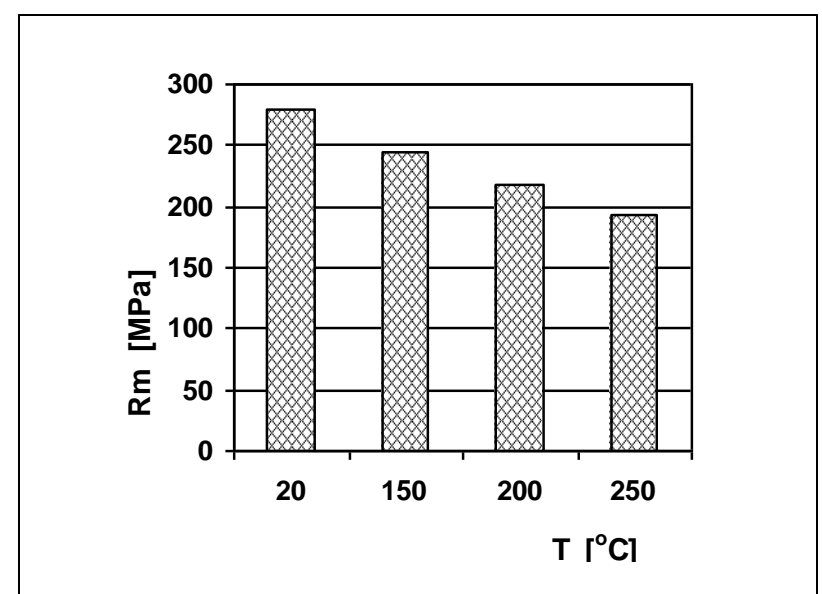

Fig. 1. Temperature course of tensile strength $R_{m}$

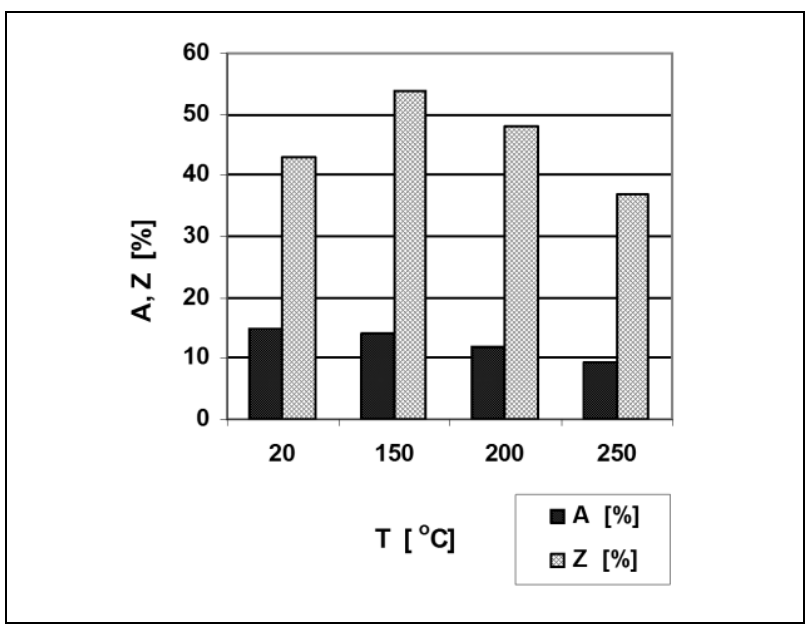

Fig. 2. Temperature courses of percentage reduction of area $\mathrm{Z}$ and ductility A

\begin{tabular}{|c|c|c|c|c|}
\hline $\mathrm{T}\left[{ }^{\circ} \mathrm{C}\right]$ & 20 & 150 & 200 & 250 \\
\hline $\mathrm{n}$ & 0,079 & 0,061 & 0,037 & 0,011 \\
\hline
\end{tabular}

Tab. 2. Values of strain hardening index $n$

Temperature course of tensile strength $R_{m}$ is illustrated in Fig. 1 and temperature courses of percentage reduction of area $\mathrm{Z}$ and ductility A are in Fig.2. Temperature courses of index of plasticity according to Kolmogorov $\lambda_{R}$ and Paur`s index of forming capacity $D_{s m}$ are demonstrated by Fig.3. Determined values of strain hardening index at examined temperatures includes Table 2 . 


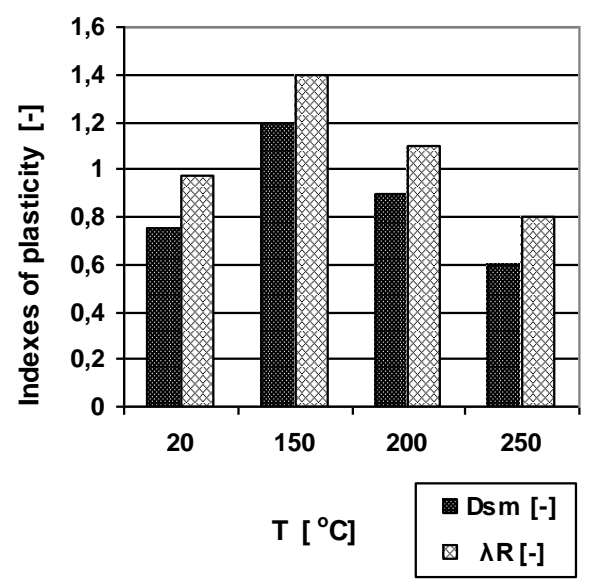

Fig. 3. Temperature courses of index of plasticity $\lambda_{R}$ and forming capacity $\mathrm{D}_{\mathrm{sm}}$

\section{NUMERIC SIMULATION}

Numeric simulation of upsetting forming process was exercised to find out material plastic flow at warm forming temperatures. A simulation software MSC SuperForge was used with application of finite element method. The input parameters for numeric simulation were: forming on hydraulic press, tool temperature $100^{\circ} \mathrm{C}$, friction coefficient 0,4 , cylindrical bar (semi-product) from aluminium alloy 6060 with diameter $25 \mathrm{~mm}$ and height $50 \mathrm{~mm}$, warm temperatures 150 , 200 and $250^{\circ} \mathrm{C}$, semi-product height after deformation $30 \mathrm{~mm}$. The simulation process enabled to observe these results: effective plastic strain, temperature in longitudinal section in the middle of cylindrical bar and contact pressure. In Fig. 4 courses of strain, temperature and pressures during upsetting process simulation are represented. During deformation at $250^{\circ} \mathrm{C}$ in the middle of the workpiece the temperature of the material increased to $270^{\circ} \mathrm{C}$, which exceeds the recrystallization temperature and recrystallization may pass. This result was also experimentally verified. Warm forming of the real part from aluminium alloy at $250^{\circ} \mathrm{C}$ was realized at the same basic parameters as are described hereinbefore. Its microstructure was observed on a light microscope on metallographic cut of longitudinal section in the middle of cylindrical bar. Degree of planar grain boundaries orientation caused by deformation was measured using oriented test lines method (Martinkovic, 2011). In all places on metallographic cut degree of orientation was in very good coincidence with numeric simulated effective strains with exception of area in the middle of the specimen.

\section{DISCUSSION}

From the result of mechanical testing at warm temperatures we can see that the best plastic properties of $\mathrm{Al}$ alloy are at $150^{\circ} \mathrm{C}$, on the other hand tensile strength has the maximum value. From the values of strain hardening index is evident, that area of equilibrium plastic deformation at temperature $200^{\circ} \mathrm{C}$ rapidly decreased. Numeric simulation of upsetting process at warm temperatures 150,200 and $250^{\circ} \mathrm{C}$ showed very good material flow. At $250^{\circ} \mathrm{C}$ during deformation the temperature of the material in the middle of the workpiece increased to $270^{\circ} \mathrm{C}$ (see Fig. 4b), which exceeds the recrystallization temperature which was verified by microstructural analysis. Microstructural analysis also showed coincidence of numeric simulation with real state. The result showed possibilities of forming of aluminium alloy of group " 6000 " in natural state at warm temperature. As optimal warm forming temperature for the alloy $\mathrm{AlSiMg} 200^{\circ} \mathrm{C}$ is recommended. In comparison with $150^{\circ} \mathrm{C}$ is at this temperature lower plasticity, on the other hand lower strength and lower contact pressure (see Fig. 4c, d). It leads to higher lifetime of tool and lower energy consumption .

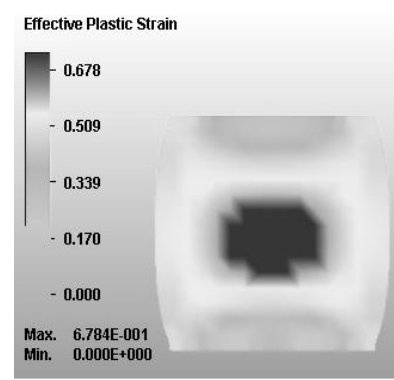

$\mathrm{c}$

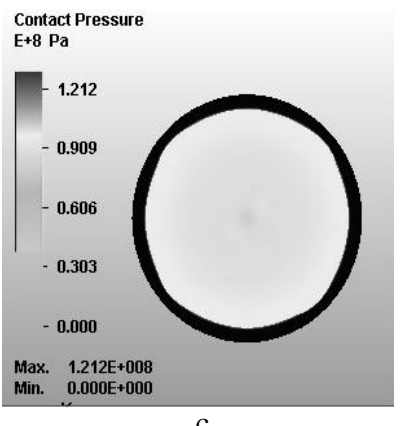

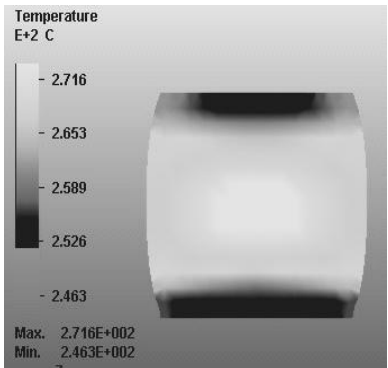

b

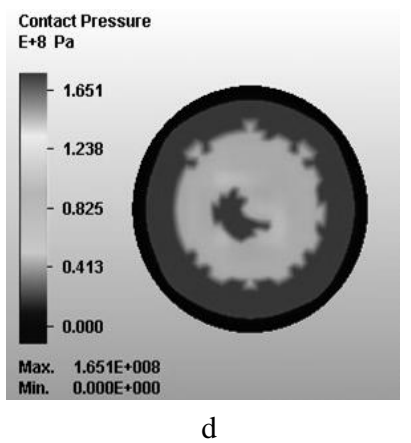

Fig. 4. Results of upsetting process simulation at $250^{\circ} \mathrm{C}(\mathrm{a}, \mathrm{b})$, $200^{\circ} \mathrm{C}(\mathrm{c})$ and $150^{\circ} \mathrm{C}(\mathrm{d})$

\section{CONCLUSION}

On the basis of mentioned results it is possible to apply the technology of warm forming. The results of numeric simulation confirm that the choice of the temperature $200{ }^{\circ} \mathrm{C}$ at warm forming was correct. Forming of aluminium alloy in natural state at warm temperature leads to time and energy consumption saving in comparison with hot forming. Also warm forming leads to better surface quality and higher dimension precision of forming pieces.

Contribution is realized with the support of the project "Centre for Development and Application of Advanced Diagnostic Methods in Processing of Metallic and Nonmetallic Materials", ITMS:26220120014, OP Research and development (implementation of project activities 05/2009 - 07/2011).

\section{REFERENCES}

Forcellese, A. \& Gabrielli, F. (2000). Warm forging of aluminium alloys: a new approach for time compression of the forging sequence. International Journal of Machine Tools and Manufacture, Vol. 40 (2000), pp. 1285-1297, ISSN 0890-6955

Forejt, M. \& Piska, M. (2006). Theory of machining, forming and tools, CERM, ISBN 80-214-2374-9, Brno

Martinkovic, M. (2011). Quantitative analysis of material structure, STU Bratislava, ISBN 978-80-227-3445-5, Bratislava

Novotny, K. (2000). Possibilities of warm forming application, Proceedings of 5th International Conference FORM 2000, September 19 - 20, Brno, ISBN 80-214-1661-0, pp. 211213, TU Brno, Brno

Pernis, R. (2007). Theory of metal forming, TnUAD, ISBN 978-80-8075-244-6, Trencin 